ORIGINAL ARTICLE

\title{
Prevalence and Factors Associated with Pelvic Organ Prolapse among Pedestrian Back-Loading Women in Bench Maji Zone
}

\author{
Andualem Henok ${ }^{*}$
}

\section{OPEN ACCESS}

Citation: Andualem Henok. Prevalence and Factors Associated With Pelvic Organ Prolapse among Pedestrian BackLoading Women in Bench Maji Zone. Ethiop J Health Sci 2017;27(3):263. doi: http://dx.doi.org/10.4314/ejhs.v27i3.8

Received: December 4, 2016

Accepted December 6, 2016

Published: May 1, 2017

Copyright: () 2017 Andualem H., et al.

This is an open access article distributed under the terms of the Creative Commons Attribution License, which permits unrestricted use, distribution, and reproduction in any medium, provided the original author and source are credited. Funding: Mizan-Tepi University

Competing Interests: The authors declare that this manuscript was approved by all authors in its form and that no competing interest exists.

Affiliation and Correspondence:

${ }^{1}$ Department of public health, college of health sciences, Mizan- Tepi University, Mizan-Aman, Ethiopia

"Email: andualemhenok@gmail.com

\section{ABSTRACT}

BACKGROUND:It is common to see women carrying heavy loads on their back in developing countries including Ethiopia. This may have an effect on pelvic organ prolapse. The objective of this study was to determine prevalence and factors associated with pelvic organ prolapse among pedestrian back-loading women in BenchMajiZone, 2016.

METHODS:The study was conducted in Bench-MajiZone, Southwest Ethiopia, from January to March 2016. Cross-sectional study design was employed. The sample size was calculated to be 422. Women were selected by using convenientsampling technique. Interviewer-administered questionnaire was used to collect data. Binary logistic regression was used to determine factors associated with pelvic organ prolapse.

RESULT: Fifty-six (13.3\%)of the study participants had pelvic organ prolapse. The likelihood of pelvic organ prolapse was higher among women whose ages were between 31-40 years $(A O R=6.88$ : 95\% CI 1.68, 28.23), 41-50 years $(A O R=11.10: 95 \%$ CI 2.54, 48.49) and above 50 years $(A O R=35.42: 95 \%$ CI 6.94, 180.85) as compared with those who were less than 30 years. The likelihood of pelvic organ prolapse was also higher among those whose BMI was less than $18.5(A O R=2.37: 95 \% C I 1.25,4.51)$ and duration of work greater than 10 years $(A O R=4.01$ : 95\% CI 1.81, 8.89).

CONCLUSION:The prevalence of pelvic organ prolapse was high. Age, BMI and duration of work were significantly associated with pelvic organ prolapse. Urgent attention is needed from concerned bodies.

KEYWORDS: Pelvic organ prolapse; Back loading; Factors, Utero Vaginal Prolapse, Ethiopia

\section{INTRODUCTION}

Manual material handling is still quite prevalent in most occupations and virtually unavoidable during daily activities. All methods of transporting heavy loads are believed to have evolved intuitively, but major differences exist between nations and sometimes between cultures or tribes in the same nation (1).

DOI: http://dx.doi.org/10.4314/ejhs.v27i3.8 
It is common to see women carrying heavy loads on their backs in developing countries including Ethiopia. Bench MajiZone isfound in Southwest Ethiopia and is known in its dense forest. Many women lead their lives by selling firewood to residents in urban areas. They carry the wood on their back and walk on foot to homes of urban residents.

Heavy physical work has been defined as work that has high energy demands or requires some measure of physical strength. Some biomechanical studies interpret heavy work as jobs that impose large compressive forces on the spine (2).

Uterine prolapse is a condition in which the muscles and supporting ligaments holding the uterus in place get too weak to keep the uterus in position. Risk factors for uterine prolapse include, among others, pregnancy and delivery, improper delivery techniques, heavy work during and soon after pregnancy and heavy weight lifting (3).

Pelvic organ prolapse is an anatomic support defect of the pelvic viscera. It may result from a series of long term failure of the supporting and suspension mechanisms of the uterus and the vaginal wall (1). The defect in the support structures results in downward displacement of structures that are normally located adjacent to the vaginal vault (4)

This maternal health condition, besides causing great physical pain, also disrupts marital and sexual relations. Women suffering from uterine prolapse often receive physical and verbal abuse from their husbands and mothers-in-law because of the condition, with some husbands leaving or threatening to leave their wives; others incorrectly consider it indicative of venereal disease. Shy and afraid of the consequences, many women who suffer from this disease hide their problem from others for decades (5). Very high prevalence of genital and uterine prolapse has been reported among women of reproductive age throughout Sub-Saharan Africa which can be problematic, particularly for populations that are already nutritionally vulnerable (6). Risk of uterine prolapse is heightened by arduous work load and carrying heavy loads (5).
Despite the impact of heavy loading on pelvic organ prolapse, there is no study conducted on prevalence and factors associated with pelvic organ prolapse among pedestrian back loading women in Bench MajiZone. Therefore this study is expected to fill the gap.

\section{METHODS}

Study area and period: The study was conducted in Bench MajiZone, Southwest Ethiopia from January to March 2016.

Study design: Cross-sectional study design was employed.

Source population and Study population: The source population was all females in Bench MajiZone who worked on firewood sales with back-loading. The study population was all females in theZone who worked on fire woods during the data collection period.

Sample size and sampling technique: The sample size was calculated by using single population proportion formula by considering $5 \%$ margin of error and 50\% proportion. We also added $10 \%$ non-response rate. Thus, the final sample size was 422 .

The towns found in the zone were selected to find women who sell firewoods with backloading. In the selected towns, women were selected by using convenient sampling technique. To avoid repetition, their names were included temporarily.

Inclusion and exclusion criteria: Ages greater than 15 years were included in the study. Nonregular workers (women carrying wood not for the purpose of selling) were excluded from the study.

Data collection technique: Intervieweradministered questionnaire was used to collect data. In addition, the weights of loads and the weights of women were measured to determine weight of load to women ratio. The questionnaire contains background characteristics, reproductive history and reproductive health problems. Data collection was done by trained health professionals. Beam balance was used to measure the weights of the loads and the weights of women. To diagnose pelvic organ prolapsed, the WHO questions to assess pelvic organ prolapse were used. Since the data collectors met the study

DOI: http://dx.doi.org/10.4314/ejhs.v27i3.8 
participants in towns while they were loaded with firewood, it was impossible to diagnose them by using physical examination. Therefore, the diagnosis was made based on history. Each woman was asked if she had a dragging lump coming down in the vagina, lump coming out of vagina or lump felt or seen outside vagina. The presence of any of these symptoms were considered to indicate the presence of POP in this study. This was followed by other questions to determine the severity of the condition, other vaginal symptoms (7). Data was collected by two BSc (Bachelor of Science) female midwives and supervised by one MSc (Master of Science) female midwife.

Data analysis procedures: Cleaned and coded data were entered into Epidata 3.1 and exported to SPSS version 20 for analysis. Descriptive analysis was conducted to determine frequencies and percentages. Binary logistic regression was used to identify factors associated with pelvic organ prolapse. P-value less than 0.05 was considered to declare statistical significance. The data was presented in tables and pie chart.

Data quality assurance: Data quality was assured by using standardized questionnaire, by training data collectors and by recruiting trained professionals.

Ethical clearance: The ethical clearance was approved by the Research and Ethical Committee of the College of Health Sciences, Mizan-Tepi University. Official letter was requested from Bench-MajiZone administration. Informed consent was taken from the study participants. Names were used only for research purpose and removed immediately after checking repetition (double participation). Study participants were informed on the objective of the study. They were on load, and data collection was done after they were unloaded. They were paid 50 Birr (Ethiopian Currency) in compensation of the lost time.

\section{RESULTS}

Background characteristics of study participants:Among the 422 participants who were involved in this study, 173(41\%) were in the age group of 19-34 years and 130(30.8\%) were between $35-49$ years. Seventy (16.6\%) were in the age range of more than 50 years. The mean age of the study participants was $34.84 \underline{12.75}$ years.

In this study,the majority, i.e., 340(80.6\%) of the study participants were protestants and $71(16.8 \%)$ followers of traditional religions. Regarding the educational status, the majority $339(80.3 \%)$, of the participants wereilleterate. Data was collected from four towns: MizanTown (50.2\%), Sheko, Bachuma and Sheybench; each accounted for $70(16.6 \%)$ of the participants. Regarding weight of women, 181(42.9\%) of the study participants' weight was less than $40 \mathrm{kgs}$. The mean weight was $43.68 \pm 7.45 \mathrm{k} . \mathrm{gs}$. In nearly half, $212(50.2 \%)$, of the study participants, weight of load was less than $25 \mathrm{kgs}$. during data collection. The mean weight of load was $26.89 \pm 7.85 \mathrm{kgs}$. More than half, 251(59.5\%), of the study participants had heights of less than 150 cms(Table 1).

Working Habits of study participants: Among the study participants, 156(37\%) worked this job (selling firewoods in back loading) for less than 2 years, while $128(30.3 \%$ ) worked for 5-10 years. The mean year was $6.92 \pm 7.76$ years. Nearly half, $219(51.9 \%)$, of the study participants reported that it taook 30 minutes to 2 hours to reach to the town from their home, and more than one-third, $148(35.1 \%)$ ) reported more than two hours. Regarding the frequency of carrying wood, it was one to two times per week in 192(45.5\%) and three to four times per week in $193(45.7 \%$ ) of the study participants. Most of participants (88.4\%) in this study had jobs other than carrying firewood. Among these, 349(93.6\%) were farmers (Table 2). 
Table 1: Back ground characteristics of Back loading women in Bench MajiZone, 2016 (N=422).

\begin{tabular}{|c|c|c|}
\hline Variables & $\mathrm{N}$ & $\%$ \\
\hline \multicolumn{3}{|l|}{ Age } \\
\hline$<18$ years & 49 & 11.6 \\
\hline $19-34$ years & 173 & 41 \\
\hline $35-49$ years & 130 & 30.8 \\
\hline$>50$ years & 70 & 16.6 \\
\hline Total & 422 & 100 \\
\hline Mean + SD & \multicolumn{2}{|c|}{$34.84 \pm 12.75$ years } \\
\hline \multicolumn{3}{|l|}{ Religion } \\
\hline Orthodox & 11 & 2.6 \\
\hline Protestant & 340 & 80.6 \\
\hline Traditional & 71 & 16.8 \\
\hline Total & 422 & 100 \\
\hline \multicolumn{3}{|l|}{ Educational status } \\
\hline Unable to read and write & 339 & 80.3 \\
\hline Read and write & 3 & 0.7 \\
\hline 1 to 4 & 74 & 17.5 \\
\hline Above 4 & 6 & 1.4 \\
\hline Total & 422 & 100 \\
\hline \multicolumn{3}{|l|}{ Town } \\
\hline Mizan & 212 & 50.2 \\
\hline Sheko & 70 & 16.6 \\
\hline Sheybench & 70 & 16.6 \\
\hline Bachuma & 70 & 16.6 \\
\hline Total & 422 & 100 \\
\hline \multicolumn{3}{|l|}{ Weight of women } \\
\hline Less than 40 & 181 & 42.9 \\
\hline $41-60$ & 221 & 52.4 \\
\hline Above 60 & 20 & 4.7 \\
\hline Total & 422 & 100 \\
\hline Mean + SD & 43.6 & \\
\hline \multicolumn{3}{|l|}{ Weight of load (k.g) } \\
\hline Less than 25 & 212 & 50.2 \\
\hline $26-30$ & 147 & 34.8 \\
\hline $31-40$ & 21 & 5 \\
\hline Above 41 & 42 & 10 \\
\hline Total & 422 & 100 \\
\hline Mean + SD & 26.8 & \\
\hline \multicolumn{3}{|l|}{ Height of women (c.m) } \\
\hline Less than 150 & 251 & 59.5 \\
\hline $151-170$ & 150 & 35.5 \\
\hline More than 170 & 21 & 5 \\
\hline Total & 422 & 100 \\
\hline Mean + SD & 152. & \\
\hline
\end{tabular}

DOI: http://dx.doi.org/10.4314/ejhs.v27i3.8 
Table 2: Working habits of pedestrian back loading women in Bench MajiZone, 2016.

\begin{tabular}{lll}
\hline Variables & $\mathrm{N}$ & $\%$ \\
\hline Work experience & & \\
Less than 2 years & 156 & 37 \\
2-4 years & 72 & 17.1 \\
5-10 years & 128 & 30.3 \\
More than 10 years & 66 & 15.6 \\
Total & 422 & 100 \\
Mean + SD & $6.92 \pm 7.76$ & \\
Time to town from home & & \\
Less than 30 minutes & 55 & 13 \\
31-120 minutes & 219 & 51.9 \\
More than 120 minutes & 148 & 35.1 \\
Total & 422 & 100 \\
Mean + SD & $126.33 \pm 60.76$ & \\
Frequency per week & & 45.5 \\
One to two times & 192 & 45.7 \\
Three to four times & 193 & 8.8 \\
More than four times & 37 & 100 \\
Total & 422 & \\
Mean + SD & $2.77 \pm 1.5$ & \\
Frequency per day & & 93.6 \\
Once & 395 & 6.4 \\
Twice & 27 & 100 \\
Total & 422 & 88.4 \\
Have other job & & 11.6 \\
Yes & 373 & 100 \\
No & 49 & 63.6 \\
Total & 422 & 100 \\
What other job & 349 & \\
Farmer & 24 & \\
Merchant & & \\
Total & 373 & \\
\hline & & \\
\hline
\end{tabular}

Reproductive history: The majority of the women $(88.4 \%)$ were married and 354(83.9\%) had children. Ofthe latter, 159(44.9\%) had more than four children. Among these, $3(0.8 \%)$ gave birth by caesarian section. Of those who had children, nearly one-third (33.4\%) passed 6-12 months since the last birth, and $35(9.9 \%)$ passed less than six months since the last birth. Sixty-nine (16.4\%) ever faced abortion. Among these, nearly half (49.3\%) experienced it twice. Among the study participants, $18(4.3 \%)$ were pregnant during the data collection. Of these, $10(55.6 \%)$ were at the second trimester, while $8(44.4 \%)$ were at the third trimester (Table 3).

DOI: http://dx.doi.org/10.4314/ejhs.v27i3.8 
Table 3: Reproductive history of pedestrian back loading women in Bench Maji zone, 2016.

\begin{tabular}{|c|c|c|}
\hline Variables & $\mathrm{N}$ & $\%$ \\
\hline \multicolumn{3}{|l|}{ Marital status } \\
\hline Married & 373 & 88.4 \\
\hline Single & 49 & 11.6 \\
\hline Total & 422 & 100 \\
\hline \multicolumn{3}{|l|}{ Have Children } \\
\hline Yes & 354 & 83.9 \\
\hline No & 68 & 16.1 \\
\hline Total & 422 & 100 \\
\hline \multicolumn{3}{|l|}{ Number of children } \\
\hline $1-2$ & 105 & 29.7 \\
\hline $3-4$ & 90 & 25.4 \\
\hline Above 4 & 159 & 44.9 \\
\hline Total & 354 & 100 \\
\hline Mean + SD & $4.82 \pm 2.91$ & \\
\hline \multicolumn{3}{|l|}{ Mode of delivery } \\
\hline Normal & 351 & 99.2 \\
\hline $\mathrm{C} / \mathrm{s}$ & 3 & 0.8 \\
\hline Total & 354 & 100 \\
\hline \multicolumn{3}{|l|}{ Time since last birth } \\
\hline Less than 6 months & 35 & 9.9 \\
\hline 6-12 months & 118 & 33.4 \\
\hline Above 12 months & 200 & 56.7 \\
\hline Total & 353 & 100 \\
\hline Mean + SD & $21.04 \pm 15.57$ & \\
\hline \multicolumn{3}{|l|}{ Ever faced abortion } \\
\hline Yes & 69 & 16.4 \\
\hline No & 353 & 83.6 \\
\hline Total & 422 & 100 \\
\hline \multicolumn{3}{|c|}{ Frequency of abortion } \\
\hline Once & 35 & 50.7 \\
\hline Twice & 34 & 49.3 \\
\hline Total & 69 & 100 \\
\hline Mean + SD & $1.49 \pm 0.5$ & \\
\hline \multicolumn{3}{|l|}{ Current pregnancy } \\
\hline Yes & 18 & 4.3 \\
\hline No & 404 & 95.7 \\
\hline Total & 422 & 100 \\
\hline \multicolumn{3}{|l|}{ Gestational age } \\
\hline First trimester & 0 & 0 \\
\hline Second trimester & 10 & 55.6 \\
\hline Third trimester & 8 & 44.4 \\
\hline Total & 18 & 100 \\
\hline Mean + SD & $6.11 \pm 1.08$ & \\
\hline
\end{tabular}

DOI: http://dx.doi.org/10.4314/ejhs.v27i3.8 
Reproductive healthproblems: Regarding the reproductive health problems, $71(16.8 \%)$ had pain around the genitalia,while $42(10 \%)$ and $98(23.2 \%)$ had abnormal vaginal discharge and abnormal vaginal bleeding, respectively. Fifty-six (13.3\%) had pelvic organ prolapse. Among those who faced reproductive health problems, 56(83.6\%) reported as it prevented them from work, but around two third $(65.7 \%)$ did not seek treatment for the problem (Table 4). Nearly one- third of the study participants $(31.8 \%)$ were underweight according toth calculated BMIs.

Table 4: Reproductive health problems of pedestrian back loading women in Bench Maji zone, 2016

\begin{tabular}{lll}
\hline Reproductive health problems & Number & Percent \\
\hline Pain around genitalia & & \\
Yes & 71 & 16.8 \\
No & 351 & 83.2 \\
Total & 422 & 100 \\
Have abnormal discharge & & \\
Yes & 42 & 10 \\
No & 380 & 90 \\
Total & 422 & 100 \\
Have abnormal vaginal bleeding & & \\
Yes & 98 & 23.2 \\
No & 324 & 76.8 \\
Total & 373 & 100 \\
Have pelvic organ prolapse & & \\
Yes & 56 & 13.3 \\
No & 366 & 86.7 \\
Total & 422 & 100 \\
Prevent from work & & \\
Yes & 56 & 83.6 \\
No & 11 & 16.4 \\
Total & 128 & 100 \\
Seek treatment & & \\
Yes & 48 & 34.3 \\
No & 92 & 65.7 \\
Total & 140 & 100 \\
\hline
\end{tabular}

Factors associated with pelvic organ prolapse: In bivariate logistic regression analysis, the odds of experiencing pelvic organ prolapse was higher among women whose ages were between 31-40 years $(\mathrm{COR}=16.07: 95 \% \mathrm{CI} 4.47,57.73), 41-50$ years $(\mathrm{COR}=20.81: 95 \% \mathrm{CI} 6.05,71.56)$ and above 50 years $(\mathrm{COR}=56.67: 95 \% \mathrm{CI} 15.34$, 209.34) as compared with those who were less than 30 years. The odds of pelvic organ prolapse was also higher among women whose BMIs were less than 18.5 (underweight) $(\mathrm{COR}=2.91: 95 \% \mathrm{CI}$ $1.64,5.15)$, those who worked for more than 10 years $(\mathrm{COR}=4.68: 95 \% \mathrm{CI} 2.27,9.65)$ as compared to those women whose BMIs were normal and worked for less than 2 years, respectively.

A multivariate logistic regression was done to assess factors associated with pelvic organ prolapse. After adjusting for potential the confounding factor of age, BMI and duration of work were significantly associated with pelvic organ prolapse. The likelihood of pelvic organ prolapse was higher among women whose ages were between $31-40$ years $(\mathrm{AOR}=6.88: 95 \% \mathrm{CI}$ $1.68,28.23), 41-50$ years $(\mathrm{AOR}=11.10: 95 \% \mathrm{CI}$ $2.54,48.49)$ and above 50 years $(\mathrm{AOR}=35.42$ :

DOI: http://dx.doi.org/10.4314/ejhs.v27i3.8 
95\% CI $6.94,180.85$ ) as compared with those who were less than 30 years. The likelihood of pelvic organ prolapse was also higher among those whose BMIs were less than $18.5(\mathrm{AOR}=2.37$ :
$95 \%$ CI $1.25,4.51)$, duration of work greater than 10 years $(\mathrm{AOR}=4.01: 95 \% \mathrm{CI} 1.81,8.89)$, and experiencing of abortion $(\mathrm{AOR}=2.39$ : $95 \% \mathrm{CI}$ $1.10,5.19)$ (Table 5).

Table 5: Multivariate analysis table showing associations between pelvic organ prolapse and other factors among pedestrian back loading women in Bench Maji zone, 2016.

\begin{tabular}{|c|c|c|}
\hline Variables & COR (95\% CI) & AOR*(95\% CI) \\
\hline \multicolumn{3}{|l|}{ Age } \\
\hline$\leq 30$ years & 1.00 & 1.00 \\
\hline $31-40$ years & $16.07(4.47,57.73)$ & $6.88(1.68,28.23)$ \\
\hline $41-50$ years & $20.81(6.05,71.56)$ & $11.10(2.54,48.49)$ \\
\hline$>50$ years & $56.67(15.34,209.34)$ & $35.42(6.94,180.85$ \\
\hline \multicolumn{3}{|l|}{ Parity } \\
\hline$\leq 2$ & 1.00 & 1.00 \\
\hline $2-4$ & $1.18(0.43,3.29)$ & $0.67(0.19,2.32)$ \\
\hline$\geq 5$ & $4.08(1.82,9.12)$ & $0.79(0.26,2.42)$ \\
\hline \multicolumn{3}{|l|}{ BMI } \\
\hline Underweight & $2.91(1.64,5.15)$ & $2.37(1.25,4.51)$ \\
\hline Normal & 1.00 & 1.00 \\
\hline \multicolumn{3}{|l|}{ Duration of work } \\
\hline Less than two years & 1.00 & 1.00 \\
\hline 2-10 years & $0.81(0.40,1.67)$ & $1.15(0.49,2.69)$ \\
\hline More than 10 years & 4.68(2.27, 9.65) & 4.01(1.81, 8.89) \\
\hline \multicolumn{3}{|l|}{ Time to town from home } \\
\hline Less than 30 minutes & 1.00 & 1.00 \\
\hline 31-120 minutes & $1.90(0.71,5.11)$ & $2.42(0.78,7.54)$ \\
\hline More than 120 minutes & $1.21(0.42,3.48)$ & $01.39(0.27,1.17)$ \\
\hline
\end{tabular}

*Adjusted for time from home, duration of work, weight of women, and age

\section{DISCUSSION}

Among the study participants, all the 422 completed the study giving a response rate of $100 \%$. Their ages ranges from 15 years to 65 years, with mean age of $34.84 \pm 12.75$. This may indicate that this job is practiced among all age groups of females. In this study, the data was collected from 4 towns: Bench MajiZone (50.2\% of the study participants were from Mizan Town). It was observed that the way of carrying wood was different in BachumaTown and the other three towns.

The mean weight of women was $43.68 \pm 7.45$ kilograms, and the mean weight of loads was $26.89 \pm 7.85$ kilograms. This result shows that women were carrying heavy loads as compared with their weight. This heavy load may burden them with different health problems. The burden may come not only from the heavy nature of the load but from the duration of the. The mean duration of work was $6.92 \pm 7.76$ years and $45.9 \%$ worked for more than 5 years. The minimum was 1 year and the maximum was 30 years. The long period of timegiven the heavy nature of the loads may affect the health of women negatively. In addition, the distance from home to town where they sold the wood should also be considered. More than one-third (35.1\%) walked to town for more than 2 hours, and in more than half $(51.9 \%)$, it took 30 minutes to two hours to reach to the town. Of course, this duration of time may not explain the actual burden. Since there is no specified place to sell wood, they travel a long distance for a long period of time from home to home within town until they sell it. In addition, the frequency of selling wood also matters. More than half of the study participants do this job for more than three times a week, and $6.4 \%$ do it twice a

DOI: http://dx.doi.org/10.4314/ejhs.v27i3.1 
day. In fact, for most (88.4\%) of the study participants, this is not the only job. They also have other jobs in their homes. The majority of them $(93.60 \%)$ were farmers. All these are possible burdens which may affect the health of women.

On top of this, $88.4 \%$ of the women were married and $83.9 \%$ had children. Among these, $44.9 \%$ had more than 4 children. These characteristics of the study participants may aggravate the problems particularly reproductive health and musculoskeletal health problems.

In addition to wood, many women also carry their small kids when they go to town. In other cases, there were women who carried wood while they were pregnant. This may have a dangerous effect on both the women and their fetuses. This study revealed that $4.3 \%$ of the women were pregnant, and of these, $44.4 \%$ were at the third trimester. In fact, women at first trimester were reported to be 0 . This could be due to lack of knowledge about whether they are pregnant or not. This is because in rural Ethiopia, many women do not know the last date of their menstrual period.

In this study, 56(13.3\%) of the women had pelvic organ prolapse. This magnitude is higher than the study conducted in ImuState University Teaching Hospital (Nigeria) which indicated that $3.9 \%$ of total gynecological admissions had pelvic organ prolapse (8). It is also higher a study conducted in TribhumUniversity Teaching Hospital (Nepal) which indicated that $2.6 \%$ of had pelvic organ prolapse (9).

A systematic review done on epidemiology and outcome assessment of pelvic organ prolapse showed that pelvic organ prolapse was $3-6 \%$. This is lower than the finding of our study (10). This may be due to the difference in population,since the population in this study was carrying heavy loads for long periods of time.

In this study, age was significantly associated with pelvic organ prolapse. This goes in line with the study conducted in NmandiAzikweUniversity Teaching Hospital (SE Nigeria) (11) and a community based study done in Kaski district of Nepal (12).

As limitation of the study, since diagnosis was made entirely based history the magnitude of pelvic organ prolapse may be under estimated. This is because the early stages may be missed. It is also difficult to classify types of pelvic organ prolapse.

This study showed that lower BMI was significantly and positively associated with pelvic organ prolapse. This issupported by findings from other study (13). Based on the result of this study, we conclude that the prevalence of pelvic organ prolapse was high. Age, BMI and duration of work were significantly associated with pelvic organ prolapse. Therefore, the local government should work to empower women to search for other sources of income. Health institutions should provide education on the importance of early treatment for pelvic organ prolapse. The local media need to provide education on health risk of carrying heavy wood. The local government should also allocate special market place to sell wood.

\section{REFERENCES}

1. Babatunde O,Adegoke A, Regina O. etal. Spinal deformities among professional load porters in a Nigerian urban market. Journal of Environmental and Occupational Science 2014; 3(2): 109-13. DOI: $10.5455 /$ jeos.20140328035014

2. Centers for Disease Control and Prevention. Musculoskeletal Disorders and Workplace Factors: A Critical Review of Epidemiologic Evidence for Work-Related Musculoskeletal Disorders of the Neck, Upper Extremity, and Low Back 1997.

3. ThapaB, RanaG, GurungS. Contributing Factors Of Utero-Vaginal Prolapse Among Women Attending In Bharatpur Hospital. Journal of Chitwan Medical College 2014; 4(9):38-42.

4. GumangaS, MunkailaA and MalechiH.Social Demographic Characteristics Of Women With Pelvic Organ Prolapse At The Tamale Teaching Hospital, Ghana.Ghana Med J 2014; 48(4): 208-13. Doi: http://dx.doi.org/10.4314/gmj.v48i4.7

5. Wan, ColferC, And PowellB. Forests, women and health: opportunities and challenges for

DOI: http://dx.doi.org/10.4314/ejhs.v27i3.8 
conservation International Forestry Review 2011;13(3):369-87.

6. Porter G, Hampshire K, and Dunn C.etal. 'Health impacts of pedestrian headloading : a review of the evidence with particular reference to women and children in subSaharan Africa.Social science medicine. 2013; 88:

90-97.

http://dx.doi.org/10.1016/j.socscimed.2013.04. 010

7. World Health Organization. Measuring reproductive morbidity: report of technical working group. Division of Family Planning 1989, (WHO/MCH/90.4).

8. Emmanuel C, Ephraim I,Frederick C,Akujiobi C, Chimezie C.Uterovaginal prolapse at a University Teaching Hospital in South-East Nigeria. Orient Journal of Medicine, 2013; 25 (3-4):107-12

9. Safe Motherhood Network Federation Prevalence of Uterine Prolapse amongst Gynecology OPD Patients in Tribhuvan
University Teaching Hospital in Nepal and its Socio-Cultural Determinants 2012

10. Matthew D. Barber M and Christopher M. Epidemiology and outcome assessment of pelvic organ prolapse. IntUrogynecol $J$ 2013;24:1783-1790 DOI 10.1007/s00192013-2169-9

11. Eleje G, Udegbunam O, Ofojebe C, and Adichie $\mathrm{C}$ Eleje. Determinants and management outcome of pelvic organ prolapse. Annals of Medical and Health Sciences Research,2014; 4 (5): 796-801

12. Tamrakar A. Prevalence of uterine prolapse and its associated factors in Kaski district of Nepal. JHAS, 2012; 2(1):38-41.

13. ProgettoMenopausa Italia Study Group. Risk factors for genital prolapse in nonhysterectomized women around menopause: Results from a large cross-sectional study in menopausal clinics in Italy.Eur $J$ ObstetGynecolReprodBiol, 2000;93(2):13540. 